\title{
Islamisierung bei den Albanern - zwischen Forschungsfrage und Diskurs
}

\author{
Oliver Jens Schmitt
}

Die Albaner sind heute die einzige autochthone, mehrheitlich muslimische Nation Europas - wenn man die junge Nationsbildung der bosnischen Muslime hier nicht für einen historischen Vergleich heranzieht. ${ }^{1}$

Sowohl die Forschung wie auch eine seit einigen Jahren recht heftig ausgetragene gesellschaftliche Debatte in den albanischen Gesellschaften im Balkan und in der Diaspora fragen nach den Gründen dieser Sonderstellung der Albaner besonders im südosteuropäischen Vergleich. ${ }^{2}$ Die gesellschaftliche Diskussion bewertet zudem den Übertritt zum Islam kontrovers. Der vorliegende Aufsatz versucht vor allem, die gesellschaftlichen und politischen Rahmenbedingungen der einschlägigen Forschung herauszuarbeiten; demgegenüber muss die eingehende Erörterung der eigentlichen Forschungsergebnisse zurücktreten, da sie den vorgegebenen Rahmen sprengen würde. ${ }^{3}$ Immerhin soll eine grobe Skizze Anhaltspunkte der Forschungsthemen bieten. Das Augenmerk gilt vornehmlich der albanischen Forschung, die wegen der jahrzehntelangen Isolierung der Volksrepublik Albanien von der internationalen Forschung getrennt und als eigenes Untersuchungsobjekt angesehen werden kann.

Historische Forschung und gesellschaftliche Bewertung der Islamisierung können besonders im albanischen Raum selbst nur schwer getrennt werden. ${ }^{4}$ Dafür war die Ideologisierung der institutionell erst nach 1945 ins Leben gerufenen Wissenschaft zu stark. ${ }^{5}$ Die Geschichtsdeutung im kommunistischen Albanien wurde maßgeblich durch unmittelbare Eingriffe des Diktators Enver Hoxha in die Arbeit der Historiker geprägt. Die kommunistische Deutung der Religionsgeschichte beruhte auf mehreren grundsätzlichen Überlegungen, die

1 Dies nach dem Titel des grundlegenden Werks von Clayer 2007; s. auch Clewing 2006; Schwandner-Sievers / Fischer 2002; Clayer 2002a. Die im Folgenden gegebenen bibliographischen Hinweise können das Thema auch nicht ansatzweise erschöpfen.

2 Sulstarova 2006; Kadare 2006. Zur Diskussion s. Ceka 2006 und Schmitt 2008a.

3 Zum Stand der Forschung s. Egro 2010.

4 Fuga, „Stereotipa mbi besimet fetare në albanologii“, erschienen in der Zeitung Gazeta Standard, abrufbar auf http://www.peshkupauje.com/2010/12/stereotipa-mbi-besimetfetare-ne-albanol - (zuletzt gelesen am 2.3.2011).

5 Eine kritische Geschichte der albanischen Osmanistik hat vor kurzem vorgelegt: Egro 2007; zur albanischen Historiographie s. auch Schmitt 2005; Schmitt / Frantz 2009, darin: Schmidt-Neke 2009. 
sich weniger aus dem Marxismus, als aus der albanischen Nationalbewegung speisten. ${ }^{6}$ Erstens seien die Albaner ein religiös indifferentes Volk; zweitens seien sie religiös besonders tolerant; drittens sei die Nationszugehörigkeit wichtiger als der Glaube; viertens seien alle Religionen Glaubenssysteme, die den Albanern von fremden Eroberern übergestülpt worden seien. Die ersten drei Elemente wurden von den Vordenkern der Nationalbewegung entwickelt, die Angehörige einer Sprachgruppe, die sich auf vier Religionen bzw. Konfessionen (oder auffallende Sonderformen einer Religion) - hier aufgelistet nach ihrer Bedeutung Ende des 19. Jahrhunderts: sunnitischer Islam, Anhänger von Derwischorden (wobei die Bektashi eine herausgehobene Stellung einnahmen), die orthodoxe und die katholische Kirche - verteilten, zu einer einheitlichen Nation zusammenführen wollten und dies in einem Umfeld zu bewerkstelligen hatten, in welchem Religions- und Nationszugehörigkeit als Einheit empfunden wurden - so in Griechenland, Serbien, Bulgarien. Die vierte Vorstellung vom Importcharakter der Religion ging aber in ihrer letzten Folge über das hinaus, was die nationalen Vordenker anstrebten: das völlige Verbot der Religionen durch das Regime Enver Hoxhas, die brutale Verfolgung aller Glaubensformen, die Verkündung einer „Zivilreligion“ in Gestalt des albanischen Nationalismus, der Bruch mit den kulturellen Wurzeln, um nach dem Vorbild der chinesischen Kulturrevolution einen „Neuen Menschen“ zu schaffen. ${ }^{7}$

Während führende - nicht alle - Vordenker der Nationalbewegung der Religion im Vergleich zur Nation einen nachgeordneten Rang zuwiesen, diese aber als wesentlichen Teil des eigenen kulturellen Erbes empfanden, das behutsam in die neue Nation und deren Staatlichkeit eingeschmolzen werden sollte - deutlich wird dies besonders in der Zwischenkriegszeit, als Angehörige der christlichen Minderheiten in die oft wechselnden Regierungen eingebunden wurden, gerade kirchliche Würdenträger herausragende Stellungen erhielten und christliche Kultur sich stärker entfalten konnte als vor 1912 im Osmanischen Reich (allein schon weil das Staatsoberhaupt nicht mehr den Kalifentitel trug und keine religiöse Macht beanspruchte, sondern der Staat den Religionen Gleichrangigkeit zugestand) - waren die Propagandisten des Atheismus gezwungen, Religion an sich herabzusetzen. Der kommunistische Kampf gegen die Religionen nahm dabei je nach Glaubensgemeinschaft einen eigenen Charakter an: die katholische Kirche wurde als Vertreterin des Abendlands und westlicher Kultur, vor allem aber als politischer und weltanschaulicher Gegner des Kom-

$6 \quad$ Clayer 2009.

7 Ceka 2010; Idrizi 2010, (einsehbar unter http://othes.univie.ac.at/9344/1/2010-0413_0409931.pdf); Tönnes 1980. 
munismus schwer verfolgt ${ }^{8}$; der sunnitische Islam besaß keinen hierarchischen Mittelpunkt, der dem Kommunismus hätte gefährlich werden können. ${ }^{9} \mathrm{Ihm}$ hing aber die Mehrheit der Albaner an, die noch 1914 für den Islam und den Sultan in Istanbul gegen einen europäischen Fürsten - Wilhelm von Wied - in einen Glaubenskrieg gerufen werden konnten. ${ }^{10}$ Stellte der Katholizismus eine gefährliche Kulturkonkurrenz dar, wurde der Islam als Symbol der Zugehörigkeit zum rückschrittlichen und barbarischen Orient empfunden, von dem sich Albanien lösen müsse. Wie die kemalistische Türkei hatte Albanien schon in der Zwischenkriegszeit begonnen - freilich behutsamer als Atatürk dies tat - eine Umorientierung nach Westen vorzunehmen, etwa die Propagierung eines Staates ohne Staatsreligion oder durch die Entschleierung der Frau. ${ }^{11}$ Im Gegensatz aber zur kemalistischen Türkei vertrat der neue albanische Staat keinen radikalen Laizismus; allein schon die Errichtung mehrerer neuer Moscheen in der Zwischenkriegszeit - die allein durch ihre Betonbauweise einen „modernen“ und reformierten Islam darstellen sollten - deutet darauf hin..$^{12}$ Der Kommunismus sah in seinem manichäischen Weltbild im Orient das grundsätzlich Schlechte und bekämpfte diesen mit großer Heftigkeit, die aber, da eine Bedrohung des Regimes durch einen politischen Islam nicht bestand, im Vergleich mit der katholischen Kirche eher die Religion als deren Vertreter traf. Im offiziellen Geschichtsbild verfestigte sich die Überzeugung, dass der Islam und das mit ihm verbundene osmanische Reich eine besonders dunkle Zeit der nationalen Vergangenheit darstellten, womit sich das albanische Geschichtsbild kaum von jenem der benachbarten christlichen Balkanstaaten unterschied. Die volksrepublikanische Geschichtsschreibung musste die eigentlich prägende Phase der albanischen Geschichte, die rund 500 Jahre währende Osmanenzeit, in doppeltem Sinne schwärzen: zum einen, indem sie ganz in den Schatten der Skanderbegund der „Rilindja“-Epoche gestellt wurde, beides Phasen des Kampfes bzw. der Ablösung vom Osmanischen Reich; zum anderen, indem sie in dunklen Farben dargestellt wurde..$^{13}$ Der geringe Platz, den die Osmanenzeit bis heute in Handbüchern im Vergleich zur vor- und nachosmanischen Zeit einnimmt, ist allein schon bezeichnend. Im Sinne eines marxistischen Geschichtsbildes wurde Religion bestenfalls als gesellschaftliches und wirtschaftliches Phänomen wahrgenommen - eine eigentliche Religionsgeschichte wurde nicht betrieben. An

8 Peters 2007. Aus dem kaum übersehbaren Schrifttum als repräsentative Beispiele: Kurti / Sirdani 1999; Ahmeti 1994.

9 Basha 2010.

10 Siehe die marxistische Deutung bei Shpuza 1979.

11 Clayer 2008; Morozzo della Rocca 1990.

12 Clayer 2010.

13 Ausführliche Diskussion bei Egro 2007. 
der Frage der Islamisierung kamen aber auch die albanischen Parteihistoriker kaum vorbei - sie bewerteten sie, wenig überraschend, als negativ. Auch heute noch geht die albanische Historiographie von der Nation als diachron stabiler Einheit aus, die von äußeren Einflüssen bedroht wird. Gerade den Religionen wird ein „Spaltpotential“ unterstellt ${ }^{14}$, da sie Angehörige der Nation in andere politische und kulturelle Zusammenhänge einfügen und die Einheit der Nation sprengen könnten. Islamisierung wird daher als politischer und gesellschaftlicher Vorgang gewertet, die Einflüsse des Islam auf die Albaner werden selbst aber möglichst gering veranschlagt. Typisch hierfür ist die These, es habe sich bei den Albanern ein „Volksislam“ herausgebildet, „fern von Intoleranz und doktrinärem Fanatismus". ${ }^{15}$ Dauerhafter Grundzug jeder Deutung von Religion war, dass diese am eigentlichen Glauben, welcher der Nation galt, abprallen musste. Entsprechend feierten die Historiker religiöse Abweichler als sozial eingestellte Vorkämpfer der albanischen Nation, ob dies nun der völlig überschätzten Rolle dualistischer Strömungen im Mittelalter galt ${ }^{16}$ - wo sich das albanische mit dem bosnjakischen Geschichtsbild berührt - oder der Vorstellung, die Nation habe alle Unterschiede der monotheistischen Religionen gleichsam abgeschliffen und in einen vagen Volksglauben mit auf allen Seiten starken synkretistischen Elementen überführt. In der Phase des offiziellen Atheismus (1967-1990) fielen auch diese Nuancen weg.

Konnten in der bis zum Schluss totalitär regierten Volksrepublik Albanien keine abweichenden Stimmen geäußert werden, galt dies für die Albaner im sozialistischen Jugoslawien - zumindest in einzelnen Phasen - weniger. Als nach 1966 gegenüber den Albanern besonders im Kosovo ein politisches und kulturelles Tauwetter einsetzte, verschafften sich Albaner in der jugoslawischen Wissenschaftswelt mehr Gehör. Zwar wurden wissenschaftliche Einrichtungen im Kosovo mit der zeitweiligen Entwicklungshilfe aus der Volksrepublik Albanien errichtet, was auch den Überbau des dortigen kulturrevolutionären Geschichtsbilds erklärt, doch zeigte sich, dass besonders die kosovoalbanischen Orientalisten nicht bereit waren, die Verdammung des osmanischen Reiches und des Islams widerspruchslos zu übernehmen. ${ }^{17}$ Dies hatte mehrere Gründe: Erstens beschränkte das sozialistische Jugoslawien seinen Krieg gegen die Religionen, der vor allem die katholische Kirche in Slowenien und Kroatien zum Opfer hatte, nach dem Bruch Titos mit Stalin (1948) ${ }^{18}$; zweitens wirkte im Kosovo eine kleine Gruppe muslimischer Gelehrter, die in der Zwischenkriegs-

14 Vgl. Historia e popullit shqiptar. Bd.1, 2002, 607.

15 Ebd.

16 Ceka, 2010, 218.

17 Schmitt 2008b, 238-245.

18 Boeckh 2005. 
zeit eine gründliche Ausbildung in den orientalischen Sprachen erhalten hatten und sich ihrer Religion eng verbunden fühlten; drittens bestand im Kosovo weitgehend die Gleichung Religions- ist auch Nationszugehörigkeit, da mit Ausnahme einer kleinen Gruppe von Katholiken alle Albaner Muslime waren die Zugehörigkeit zum Islam kennzeichnete die Identität der Jugoslawienalbaner viel mehr als jene der Albaner im „Mutterland“, die zum einen eine größere religiöse Vielfalt kannten, zum anderen unter dem Einfluss eigener Staatlichkeit und einer eigenen Religionspolitik standen. In Jugoslawien hingegen bildete der Islam nicht nur den Kern der Identität, sondern auch, neben der Sprache, den entscheidenden Unterschied gegenüber dem dominanten Staatsvolk und ethnischen Konkurrenten, den Serben. Der Islam bot den Jugoslawienalbanern in den Jahrzehnten der Repression (1918-1941; 1945-1966) den einzigen institutionellen Rückhalt. Viertens blieben die Beziehungen zur Türkei nach 1912 viel enger als in Albanien; diese wurden durch mehrere unter Druck erfolgende Auswanderungswellen von muslimischen Albanern in die Türkei, sowohl in der Zwischenkriegszeit als in der Frühzeit von Tito (fünfziger Jahre), verstärkt. Insgesamt waren die Kosovoalbaner bis zum Einsetzen der Massenauswanderung besonders nach Mittel- und Nordeuropa viel mehr dem Orient zugewandt, als dies in Albanien der Fall war. Die Verbundenheit mit dem Islam und dem Osmanischen Reich zum einen, eine jahrhundertelange Erfahrung von Grenzlage zu Serbien und Montenegro sowie von Repression in den beiden jugoslawischen Staaten zum anderen schufen einen besondere Empfindlichkeit bei der Bewertung des Islam. Der Orientalist Hasan Kaleshi vertrat in einem 1975 in München veröffentlichten, aber auch auf dem Balkan sehr beachteten Aufsatz die These, dass die Islamisierung nicht negativ zu bewerten sei, sondern im Gegenteil die Albaner von der Assimilierung an die orthodoxen Griechen und Serben bewahrt habe. ${ }^{19}$ Kaleshis Auffassung ist vor dem Hintergrund der sog. Arnautaši-These serbischer Nationalisten zu bewerten, wonach die muslimischen Nordalbaner islamisierte und albanisierte Serben seien, die, wenn nötig, auch mit Gewalt, zu ihren vermeintlichen Ursprüngen zurückgeführt werden müssten. Kaleshi sah im Islam keinen Fremdkörper, sondern vielmehr eine Nationalreligion im Gegensatz zu den Nationalreligionen der Serben und Griechen, deren Kirchen Ethnopolitik betrieben, indem sie über Gottesdienst und Liturgiesprachen anderssprachige Angehörige derselben Religion ethnisch assimilierten. Kaleshi ging von der angesprochenen, fast vollständigen religiösen Einheitlichkeit der Jugoslawienalbaner aus und berücksichtigte die weitaus komplexeren religiösen Verhältnisse jenseits der Berge, in Albanien selbst, nicht. Seine These sprengte den albanischen Konsens einer überreligiösen, ganz auf Sprache, Herkunft

19 Kaleshi 1975; und noch jüngst Xhufi 2006, $272 \mathrm{ff}$. 
und Geschichte gegründeten Identität. Sie richtete sich auch gegen die Säkularisierung von Identität. So heftig die Ablehnung bei den laizistischen albanischen Eliten auch war, spiegelte die These die Lebenserfahrung Kaleshis wider, d.h. das bis in das letzte Drittel des 20. Jahrhunderts sehr stark religiös geprägte Selbstverständnis der Jugoslawien-Albaner, das heute noch bei den MakedoAlbanern fortbesteht und wiederholt Anlass zu heftiger Kritik laizistischer bzw. westlich ausgerichteter Intellektueller bietet. ${ }^{20}$

Vor diesem Hintergrund kann nun die Annäherung an eine kurze Übersicht über die eigentliche Forschung erfolgen. $\mathrm{Zu}$ unterstreichen ist, dass sich mit der Islamisierung bei den Albanern auch nichtalbanische Orientalisten in Jugoslawien beschäftigten, die im Gegensatz zu nicht orientalistisch ausgebildeten Historikern weniger in nationalen Schablonen dachten. Diese Studien wurden auch außerhalb des albanischen Siedlungsraumes betrieben, nicht zuletzt von der Münchner Schule um Georg Stadtmüller ${ }^{21}$ und Peter Bartl..$^{22}$ Während im Balkan vor allem Orientalisten zur Islamisierung bei den Albanern arbeiteten, forschten mittel- und südeuropäische Gelehrte besonders in italienischen Archiven, allen voran den Archiven des Vatikan und der 1622 geschaffenen Congregatio de Propaganda fide, die für die katholische Kirche und Missionen im osmanischen Reich zuständig war. ${ }^{23}$

Die Historiker beschäftigten sich mit mehreren grundlegenden Erscheinungen der Islamisierung: 1) der zeitlichen Periodisierung; 2) den erheblichen regionalen und teilweise auch kleinregionalen/lokalen Unterschieden dieses Prozesses; 3) den Gründen der Islamisierung; 4) der Bedeutung der im osmanischen Vergleich starken Stellung der Derwischorden, allen voran der Bektashi, und deren nationalpolitischer Bedeutung; 5) synkretistischen Erscheinungen und dem Phänomen des Kryptochristentums. Es ist bei der Knappheit des zur Verfügung stehenden Raumes nicht möglich, all diese Forschungsfragen tiefschürfend zu ergründen. Einige Striche seien aber dennoch gezogen.

20 Siehe die Debatte auf dem albanischen Fernsehsender Klan TV über makedonische Identität http://www.youtube.com/watch? $\mathrm{v}=\mathrm{nUAwy} 5 \mathrm{TdiEE}$ (zuletzt gesehen am 8.3.2011), besonders die Polemik zwischen Maks Velo und Menduh Thaçi; Velo sprach dabei von einer „extremen Islamisierung“ der Albaner in Makedonien, kritisierte die „Diskriminierung der Frauen“ und den niedrigen Bildungsstand.

21 Stadtmüller 1955.

22 Siehe den jüngsten Aufsatz: Bartl 2010.

23 Hier sei pauschal auf das Lebenswerk Peter Bartls verwiesen; P. Bartl arbeitet an einer auf 5 Bände angelegten Edition der Albania sacra. 


\section{Zeitliche Periodisierung und regionale Verteilung der Islamisierung}

Die albanischen Siedlungsgebiete wurden schon früh von osmanischen Heeren erreicht. Rund dreißig Jahre nach dem ersten Auftreten der Osmanen bei Gallipoli (1354) schlugen osmanische Verbände in der mittelalbanischen Myzeqejaebene das regionale Adelsgeschlecht der Balsha (1385). ${ }^{24}$ Frühe Eroberung bedeutete aber nicht schnelle Beherrschung des Gebietes. Erst Bajezit II. gelang es 1492, die letzten Widerstandsnester zu unterwerfen. In den rund eineinhalb Jahrhunderten zwischen diesen beiden Eckdaten kam es im albanischen Siedlungsraum zu mehreren großen Aufständen gegen die Osmanen, von denen die Erhebung Skanderbegs die längste wie berühmteste ist. Skanderbegs Erhebung kann als sinnbildlich für die erste Phase der Islamisierung gesehen werden ${ }^{25}$ : Diese betraf vor allem Angehörige des regionalen Adels, der seine Söhne als Geiseln an den Sultanshof zu schicken hatte oder der zur Bewahrung seines Einflusses den Glauben wechselte. Die Einbindung von Teilen des Adels verlief über das Timarsystem, in das gerade im albanischen Siedlungsgebiet im 15. Jahrhundert auch Christen - freilich mit bescheideneren Einkünften - aufgenommen wurden. So finden sich auch christliche Geistliche als Timarioten. Um 1430 schien die sehr dünne islamisierte Elite fest in das osmanische Reich eingegliedert. Der Aufstand brach aus, da sich unter diesem Firnis mehrere Konfliktlinien abzeichneten: erstens unter den islamisierten Albanern rivalisierten Angehörige alter Familien mit gesellschaftlichen Aufsteigern, wobei erstere ihren Besitz verteidigten und um diesen auch fürchten mussten, letztere aber nur zu gewinnen hatten und dem Sultan weitaus größere Treue bezeugten; der Aufstandsführer Skanderbeg, ein islamisierter osmanischer Offizier, wurde durch die Hinrichtung seines Vaters durch den Sultan persönlich beleidigt und stand zudem in Konkurrenz zu anderen osmanischen Offizieren, mit denen er bis zum Ende seines Lebens in Fehde lag; Breitenwirkung erreichten diese Spannungen im osmanischen Offizierskorps aber, weil Bevölkerungsschichten vor allem in Berggebieten zentralisierende Maßnahmen des osmanischen Reiches ablehnten, insbesondere den $\mathrm{Zu}-$ griff der osmanischen Steuerverwaltung und die Durchsetzung des osmanischen Rechts, besonders des Bodenrechts. Die Aufständischen nahmen alle wieder das Christentum an; da alle Rebellen Christen waren (oder wieder wurden), ihre Gegner, die Anhänger des Sultans, überwiegend - auf der Führungsebene ausschließlich - Muslime waren, verliefen die Fronten entlang der Religionsgrenzen

24 Überblick bei Schmitt 2001.

25 Ich erlaube mir, für die Forschungsdiskussion zu verweisen auf: Schmitt 2009. 
besonders zwischen katholischem Glauben und Islam, während sich Orthodoxe auf beiden Seiten fanden und die orthodoxe Kirche im Gegensatz zur katholischen die Erhebung nicht unterstützte. Die Ausbreitung und die lange Dauer des Aufstands verstärkten besonders in der südeuropäischen und osmanischen Wahrnehmung den religiösen Charakter der Kämpfe, die auf regionaler Ebene eine Auseinandersetzung zwischen pro- und antiosmanischen Teilen des einheimischen Adels und der einheimischen Gesellschaft darstellten. Der Aufstand wurde von Sultan Mehmed II. mit größter Brutalität niedergeworfen; zwischen zwei Dritteln und drei Vierteln der Aufständischen wurden getötet, deportiert oder flohen in die Berge oder nach Italien; die nordalbanische katholische Städtewelt wurde von den Osmanen gezielt zerstört. Die Verwüstungen waren so umfassend, dass von einem eigentlichen kulturellen Schock gesprochen werden kann, der sich auch darin äußerte, dass die Albaner in einem längeren Prozess, der mit der Islamisierung parallel voranschritt, ihre Eigenbezeichnung änderten: Arbër, das den christlichen Albaner bezeichnete, wurde durch ,shqiptar“ ersetzt, eine auch im europäischen Vergleich wohl einzigartige Erscheinung. ${ }^{26}$ Festzuhalten ist, dass die für die albanische Kulturentwicklung besonders bedeutsame katholische Kirche und die mit ihr verbundene katholische Stadtkultur den Osmanen heftigen Widerstand entgegengesetzt hatte und dafür mit ihrem fast völligen Untergang bezahlte. ${ }^{27}$ Die katholische Kirche wurde auf die Landschaft, vor allem in abgelegene Abteien und Dorfkirchen im Hochland abgedrängt, aus einer städtischen wurde sie zu einer ländlichen Institution. All dies schuf erst den Boden für eine Islamisierung der Bevölkerung. Anders stellte sich die Lage im Süden des albanischen Siedlungsraums dar, der, abgesehen von Berggebieten (Himara), kaum an Skanderbegs Aufstand teilgenommen hatte. Die frühe Unterwerfung durch die Osmanen zum einen, die Einigung des orthodoxen Patriarchats von Konstantinopel mit Mehmed II. zum anderen bewirkten, dass die orthodoxe Kirche weit weniger von der osmanischen Eroberung getroffen wurde als die katholische und dass in den traditionell orthodoxen Gebieten die Kirchenverwaltung und die Betreuung der Gläubigen durch Priester aufrecht blieb. ${ }^{28}$ Der kriegsverwüstete Norden stand um 1500 einem gesellschaftlich (v.a. demographisch) und politisch gefestigten Süden gegenüber. ${ }^{29} \mathrm{Als}$ Breitenphänomen setzte der Übertritt zum Islam im Wesentlichen erst gegen Ende des 16.

26 Wie schwierig der Umgang mit dem Wechsel der Selbstbezeichnung heute noch ist, zeigt Demiraj 2010.

27 Bartl 2010; s. auch Schmitt 2000.

28 Eine literaturgesättigte Darstellung der orthodoxen Kirche im südalbanischen Raum bietet nun Giakoumis 2010.

29 Zur Geschichte des osmanischen Südalbanien siehe die Aufsatzsammlung von Duka 2009. 
Jahrhunderts ein, wiederum mit erheblichen regionalen Unterschieden. Stark islamisiert waren einige Städte, die aber ganz unterschiedlichen gesellschaftlichen und politischen Zusammenhängen zuzuordnen sind: Die größte nordalbanische Stadt Shkodra wurde 1479 von ihrer katholischen Bevölkerung weitgehend geräumt, die es vorzog, im Friaul unter venezianischer Herrschaft zu leben und dort den Kampf gegen die Osmanen weiterzuführen, als sich diesen zu unterwerfen $^{30}$; eine zweite Gruppe von Städten mit rasch steigendem muslimischem Bevölkerungsanteil lag im Kosovo und im oberen Vardartal, südslawisch-albanischen Mischgebieten. Skopje, seit dem Ende des 14. Jahrhunderts osmanische Hauptfestung im westlichen zentralen Balkan, wurde schon im 15. Jahrhundert zu einer stark muslimisch geprägten Stadt; ähnliches gilt für Tetovo im Polog, von wo aus osmanische Timarioten die Aufständischen Skanderbegs bekämpften. Die Islamisierung erfolgte auffallend früh. In Vučitrn/alb. Vushtrri bildeten 1487, rund 30 Jahre nach der Eroberung, die Muslime bereits ein Drittel der Bevölkerung. In Mittelalbanien entwickelte sich die 1466 von Mehmed II. aus dem Boden gestampfte Garnisonsstadt Elbasan zum wichtigsten städtischen Zentrum des Islams. Um 1500 gehörte die überwältigende Bevölkerungsmehrheit in den von Albanern besiedelten Gebieten aber den beiden christlichen Konfessionen, ganz überwiegend der Orthodoxie, an. ${ }^{31}$

Im 16. Jahrhundert schritt die Islamisierung der größeren Städte im heutigen Albanien und im Kosovo voran, freilich nicht gleichmäßig: Fast 100\% muslimisch war allein Shkodra, es folgten der alte serbische Patriarchensitz Peć/ alb. Peja mit 90\%, Vučitrn mit 80\%, Elbasan mit 79\%, die Verwaltungszentrale des Polog Tetovo mit 71\%, das im Süden des Polog gelegen Kičevo/alb. Kërçova mit 65\%, Skanderbegs alte Burg Kruja mit 63\%, Berat und Priština mit je $60 \%$, Prizren mit 55\% $\%^{32}$ - alle Orte besaßen eine erhebliche Bedeutung für Heer und Verwaltung. Deutlich schwächer war die Islamisierung im Kosovo im Minenort Trepča mit 21\%, im Minenort Novo brdo mit 37\%, vor allem aber im albanischen Süden: Selbst der Flottenhafen Vlora zählte nur 23\% Muslime, ein Provinzstädtchen wie Delvina nur 4\%. Hinter den Bergen freilich Tepelena $50 \%$ und Korça 21\%. Im angrenzenden Gebiet um den Ochridsee lebten gegen Ende des 16. Jahrhunderts Muslime fast nur in den Städten Ochrid und Struga. ${ }^{33}$ Um 1590 hatte der Islam in vielen Regionen deutlich Fortschritte gemacht und bildete in den wichtigsten, aber eben nicht in allen, teilweise oder mehrheitlich albanisch besiedelten Städten die Mehrheitsreligion. Im ländlichen Raum hatte

30 Nadin 2008.

31 Egro 2010, 47 rechnet für den Beginn des 16. Jahrhunderts mit einer christlichen Mehrheit von $97,8 \%$.

32 Historia e popullit shqiptar $\mathrm{Bd}$. 1, 590.

33 Gorgiev 2006/07. 
er begonnen, Fuß zu fassen, doch waren auch hier die regionalen Unterschiede stark. Ende des 16. Jahrhunderts war die große Mehrheit der Albaner immer noch christlich. Mehrere Islamisierungswellen im 17. Jahrhundert veränderten jedoch die Lage weiter zuungunsten der Christen. Allein um Prizren wechselten 1620-1624 rund 3000 Menschen den Glauben. In den 1640er Jahren brach der ländliche Katholizismus Nordalbaniens in vielen Regionen zusammen; auch Mittelalbanien wurde zunehmend islamisiert. Ein weiterer Schub erfolgte Ende des 17. Jahrhunderts, diesmal bedingt durch den habsburgischen Türkenkrieg; ebenfalls im Zusammenhang mit einem Krieg des osmanischen Reiches gegen christliche Mächte ist der weitgehende Übertritt der städtischen Bevölkerung des albanischen Süden 1735-1740 zu verstehen. ${ }^{34}$ Besonders schwer hatte es die katholische Kirche, die nach dem Krieg von 1683-1699 ein Konzil in den albanischen Bergen einberief, um die Lage zu stabilisieren (sog. Albanisches Nationalkonzil 1709) ${ }^{35} \mathrm{Im}$ 18. Jahrhundert machte die Islamisierung starke Fortschritte, in Südalbanien beschleunigt von der Politik des regionalen Machthabers Ali Pascha (st. 1822). Die Tanzimatreformen und die in den meisten albanischen Siedlungsgebieten nur auf dem Papier bestehende rechtliche Gleichstellung der Christen (1856) führten keinen Wandel herbei; der Widerstand albanischer Muslime gegen die Reformpolitik erwies sich als besonders heftig, und Christen waren in vielen Regionen Übergriffen und Benachteiligungen ausgesetzt, die im Zuge des allmählichen Machtverlusts des osmanischen Reiches und des Einströmens muslimischer Flüchtlinge aus serbisch eroberten Gebieten in den Kosovo (1877) noch an Schärfe zunahmen; gerade im Kosovo kam es noch in der zweiten Hälfte des 19. Jahrhunderts zu zahlreichen Übertritten katholischer Albaner zum Islam. ${ }^{36}$ Erst als 1912 die osmanische Herrschaft auf dem Balkan zusammenbrach, kam auch die Islamisierung zu einem Abschluss. Zu Beginn des 20. Jahrhunderts werden rund $80 \%$ aller Albaner dem Islam angehört haben; eine Statistik aus dem Staat Albanien - also ohne die fast ausschließlich muslimischen Albaner in Jugoslawien und Griechenland (Çamen) - erfasste 70\% Muslime (davon wohl rund 20\% Anhänger des Ordens der Bektashi), 20\% Orthodoxe und 10\% Katholiken. Welche Veränderungen der Atheismus, das Wiederaufleben der Religionen nach 1991 und angeblich zahlreiche Übertritte von Muslimen zum Christentum in der jüngsten Vergangenheit herbeigeführt haben, ist zahlenmäßig derzeit nicht erfassbar, da sich der albanische Staat bis

34 Überblick bei Egro 2010. Allgemein zur Lage im albanischen Süden: Duka 2009; aus einer anthropologischen Perspektive: de Rapper 2008.

35 Demiraj 2004; Radoja / Berisha 2003.

36 Bartl 1968; Reinkowski 2005; Blumi 2003; Frantz 2010. 
vor kurzem geweigert hat, in Volkszählungen auch die Religionszugehörigkeit auszuweisen. ${ }^{37}$

\section{Ursachen der Islamisierung}

Die Gründe für den Übertritt zum Islam sind in der Balkanforschung bekanntlich umstritten. Wie eingangs dargelegt, ist auch die Forschung im albanischen Fall stark ideologisiert. Dennoch sollen einige Elemente herausgearbeitet und zur Diskussion gestellt werden. Unbestritten ist, dass im albanischen Siedlungsraum die Islamisierung nicht durch Einwanderung von Muslimen (Türken und Yürüken) befördert wurde, sondern dass es sich um eine Veränderung innerhalb der regionalen Gesellschaft handelte. Die Analyse setzt sich zudem gewöhnlich mit beiden Seiten, Christen und Muslimen, auseinander und untersucht die Gründe für die Ausbreitung des Islams. Viele dabei herausgearbeitete Elemente sind keinesfalls spezifisch für den albanischen Raum. Wie in Bosnien wurde die katholische Kirche von der osmanischen Eroberung stark geschwächt; auch nach dem Ende der Kampfhandlungen stand sie in den Augen der Osmanen im Verdacht, mit Reichsfeinden, allen voran dem Papst, im Bunde zu stehen und eine Art „,ünfte Kolonne“ darzustellen; der Entfaltung der katholischen Kirche wurden daher enge Grenzen gesetzt. ${ }^{38}$ Die erwähnte Abdrängung in den ländlichen Raum zählt zu dieser Strategie. In Kriegszeiten zerstörten Muslime wiederholt katholische Kirchen, so um die Mitte des 17. Jahrhunderts, als in den schwarzen Bergen in Mittelalbanien neun von zehn Kirchen verwüstet wurden ${ }^{39}$ - aber auch bei Konflikten zwischen Muslimen, etwa der Niederwerfung der Erhebung des Shkodraner Paschas Kara Mahmud Bushatlliu, wurden zahlreiche Kirchen geplündert und niedergebrannt (1787). ${ }^{40}$ Bistümer konnten nicht mehr besetzt werden, das Priesternetz dünnte sich aus. Damit sank auch die geistliche Betreuung der Gläubigen. Priester waren in der Frühen Neuzeit für Sprengel

37 In der laufenden Volkszählung ist das Kriterium aufgenommen, was zahlreiche Befürchtungen weckt, u.a. die Vermutung, Griechenland könnte die Orthodoxen pauschal als „Griechen“ vereinnahmen und die Nordepirusfrage wieder aufbringen. http://www. shekulli.com.al/2010/02/01/regjistrimi-mbi-baze-fetare-sjell-probleme-brenda-dhejashte-kufijve.html (gelesen am 8.3. 2011); http://www.shekulli.com.al/2010/02/03/ regjistrimi-mbi-baza-fetare-ekspertet-kunder.html (gelesen am 8.3. 2011); http://www. shekulli.com.al/2010/02/06/kleri-i-percare-per-regjistrimin-me-baze-fetare.html (gelesen am 8.3. 2011).

38 Zur katholischen Kirche in der osmanischen Zeit liegt eine umfangreiche Literatur vor, siehe etwa Marlekaj 2008; Marquet 1997.

39 Bartl 2007, 91.

40 Ebd., 244; vgl. Naçi 1986; Köhbach 1986. 
zuständig, die schlicht zu groß waren, als dass sie regelmäßige Gottesdienste in den Dörfern hätten abhalten können. Gut belegt ist auch der schwindende Bildungsgrad vieler Priester, die mit den Grundlagen ihres Glaubens nicht selten schlecht vertraut waren; umso problematischer bestellt war es mit den einfachen Gläubigen. Zudem bestanden auch innerhalb der katholischen Kirche Konflikte, besonders als die Propaganda fide begann, einheimische Pfarrer genauer zu beaufsichtigen; diese schlossen sich bisweilen mit muslimischen Notabeln zusammen; so setzte 1629 dem katholischen Bischof von Lezha ein Sipahi das Messer an die Kehle, weil der katholische Ortspfarrer ihn gegen den Ausländer - Benedetto Orsini - aufgebracht hatte. ${ }^{41}$ Im 17. Jahrhundert erreichte der albanische Katholizismus seinen Tiefstand. Die Gründung der Propaganda fide, das erwähnte Reformkonzil, die seit 1718 (Friede von Passarowitz) wirksame österreichische Schutzherrschaft (Kultusprotektorat) festigte die Lage immerhin. ${ }^{42}$ Doch noch bis zur Mitte des 19. Jahrhunderts lebten Katholiken gefährdet - so zerstörten 1856 in Shkodra Muslime das im Bau befindliche katholische Priesterseminar. ${ }^{43}$ Ende des 19. Jahrhunderts hielt sich der katholische Glaube in bergigen Rückzugsgebieten Nord- und Mittelalbaniens, sowie bei Berglern, die in den Kosovo und in die nordalbanische Stadt Shkodra abgewandert waren. Anders war die Lage der orthodoxen Kirche gestaltet ${ }^{44}$; sie war zwar wegen ihrer frühen Unterwerfung privilegiert, aber in Wohl und Wehe ganz dem osmanischen Reich ausgeliefert, das um 1575 in großem Stile Kirchenbesitz beschlagnahmte. Nicht umsonst kam es um 1600 in den orthodoxen Siedlungsgebieten des Südens (vom Ochridsee bis nach Südalbanien) zu einzelnen Aufständen unter der Führung orthodoxer Geistlicher; am massivsten aber sagte sich die Orthodoxie im Kosovo vom osmanischen Reich los (1689). Die harte Niederschlagung der Aufstände der Orthodoxen - Serben wie Albaner (dazu auch der katholischen Albaner) - zwischen 1689 und 1735 verschlechterte die Lage der Orthodoxen deutlich und beendete die regionale Kirchenautonomie in Ochrid und Peć (1766/67), die aber nicht in einem albanischen Kontext einzuordnen sind, wohl aber auf albanische Orthodoxe Auswirkungen hatten. Aus diesen Bemerkungen geht hervor, dass Gewalt eine erhebliche Rolle bei der Islamisierung spielte ${ }^{45}$ : Gescheiterte christliche Aufstände belegen die geringe Akzeptanz des islamischen Osmanenstaates bei der christlichen Bevölkerung auch Jahrhun-

41 Bartl 2007, 87.

42 Dazu das materialreiche, aber unstrukturierte Buch von Deusch 2009.

43 Reinkowski 2005, 142.

44 Glabinas 1985; Kondis 1976; Peyfuss 1974; eine vorzügliche Analyse zum Entstehen ethnonationaler Identitäten im komplex geschichteten orthodoxen Süden bei Clayer 2006; s. auch Winnifrith 2002.

45 So auch Egro 2010, 48. 
derte nach der Eroberung, sie beschleunigten aber die Islamisierung zum einen durch die Flucht von Rebellen (vor allem auf österreichisches Gebiet) und den Übertritt zum Islam aus Furcht vor Repressalien; im Bergland siedelten die Osmanen als besonders unruhig bekannte Bergstämme in die Ebenen um. ${ }^{46}$ Gewalt und Zwang übte auch der bereits erwähnte Ali Pascha aus, wenngleich er auch orthodoxe Christen in sein Machtsystem einband. Nicht nur Aufstände, sondern auch Kriege, besonders solche, die das osmanische Reich verlor, radikalisierten die Haltung von Muslimen gegenüber Christen ${ }^{47}$, die aus Furcht den Glauben wechselten. In der Forschung noch wenig diskutiert ist der Zusammenhang zwischen der fundamentalistischen Gruppe der Kadizadeli, jener Rückkehr zu den Wurzeln des Islam, die etwa nach der Eroberung Kretas (seit 1645) zur Einführung des Schariarechts auf dieser Insel führte, und den gleichzeitigen massiven Islamisierungswellen in Nord- und Mittelalbanien. ${ }^{48}$ Nicht als offene, doch als strukturelle Gewalt kann die rechtliche Diskriminierung der Christen im osmanischen Reich angesehen werden; noch im 19. Jahrhundert konvertierten im Kosovo Christen mit der Begründung, der Islam sei die Religion der Herren, das Christentum jene von Sklaven..$^{49}$ Seit Anbeginn der osmanischen Herrschaft spiegelte sich die Ungleichheit in Sondersteuern für Christen wider. Lange Kriege und zunehmende militärische Niederlagen zwangen das osmanische Reich im späten 16., vor allem aber im 17. Jahrhundert zur Einführung von Sonderabgaben, die die Steuerlast der christlichen Bevölkerung deutlich erhöhten und einen Anreiz oder auch Zwang zum Glaubenswechsel schufen; im 17. Jahrhundert vermochten viele Christen die Steuerlast nicht mehr zu schultern und suchten einen Ausweg im Glaubenswechsel. Das Vorrecht der Muslime, Waffen zu tragen, zeitigte weitreichende Konsequenzen im Alltag, wo noch im späten 19. Jahrhundert etwa im Kosovo Christen muslimischen Übergriffen im städtischen Raum wehrlos gegenüberstanden. ${ }^{50}$ In den Berggebieten ließ sich die Entwaffnung der Christen freilich nicht durchsetzen, und bestimmte katholische Zuwanderer aus dem Bergland wurden im Kosovo von den Osmanen als Hilfspolizisten rekrutiert (Fandi). ${ }^{51}$ Wichtig ist im Zusammenhang mit gewaltbedingtem Glaubenswechsel hervorzuheben, dass diese Erscheinung in der osmanischen Frühzeit (15.-16. Jahrhundert) kaum zu beobachten ist und wiederum regionale Unterschiede bestanden. Herrschaftsverhältnissen kam aber eine über-

46 So um 1670 die Gashi, Bartl 2007, 127.

47 Im venezianisch-osmanischen Krieg von 1645-1669 hatten die Osmanen den Bischof von Lezha verhaftet, der von den Gläubigen nur durch die Verpfändung des Kirchenguts ausgelöst werden konnte; Bartl 2007, 128.

48 Anastasopoulos 2008.

49 Clayer 2002b.

50 Frantz 2009b; dies. 2009a.

51 Frantz 2011. 
ragende Bedeutung zu, und zwar nicht nur, wo Zwang oder Angst vor Rache im Vordergrund standen. Es wurde bereits erwähnt, dass in der frühen Phase der osmanischen Eroberung der Übertritt zum Islam weitgehend als Schritt zur Eingliederung in ein neues Reich verstanden werden kann, das Teilhabe an Macht und Beute versprach. Auch wurde hervorgehoben, dass in einer ersten Phase vor allem Angehörige der Oberschichten den Islam annahmen, um ihre gesellschaftliche Stellung zu bewahren. Im Falle der Albaner übten die Aufstiegsmöglichkeiten in der osmanischen Verwaltung und dem osmanischen Heer einen sehr starken Anreiz aus, und Albaner stellten bis zu Beginn des 20. Jahrhunderts einen bedeutenden Teil der entsprechenden osmanischen Eliten, darunter zahlreiche Großwesire. So heftig der Widerstand im 15. Jahrhundert gestaltet war, so oft es immer wieder zu kleinregionalen Rebellionen kam, so stark wurden die Albaner durch die Islamisierung in den osmanischen Reichsapparat eingebunden. ${ }^{52}$ Es ist schwer und letztlich wohl kaum möglich abzuwägen, was im Falle der Albaner die Islamisierung tatsächlich zu einem Breitenphänomen gemacht hatte, die Anziehungskraft des osmanischen Reiches oder verschiedene Formen des Zwangs; was jedoch den Quellen zufolge nicht ins Gewicht fiel, waren rein religiöse Gründe, also dass Konvertiten den Islam als überlegenen Glauben ansahen. Die Islamisierung der meisten Albaner kann, gleichgültig wie man die einzelnen Ursachen bewertet, als Ergebnis einer halbtausendjährigen Herrschaft eines islamischen Großreiches angesehen werden. Viel erstaunlicher als die starke Islamisierung ist, dass sich der christliche Glaube, der alle Christen als Untertanen zweiter Klasse dauerhaft kennzeichnete, auf dem Balkan überhaupt als Mehrheitsreligion hielt und nicht wie in den alten christlichen Gebieten Anatoliens, Syriens und Ägyptens in eine Minderheitenposition abgedrängt oder ganz zum Verschwinden gebracht wurde. Auf der anderen Seite bleibt die Frage offen, weshalb die Albaner viel stärker als etwa Serben und Griechen den Glauben gewechselt haben. Wie eingangs gezeigt, weisen die Antworten einen stark national-ideologischen Charakter auf - ob nun der Islam als „Rettung“ vor einer angeblich drohenden Slawisierung bzw. Gräzisierung angesehen wird und die vermeintliche religiöse Indifferenz bzw. Toleranz im Sinne einer synkretistischen Volksreligion ins Treffen geführt werden. Eine Deutung kann nicht in einem national-albanischen Kontext verharren, sondern muss in einem gesamtbalkanischen Vergleich durchgeführt werden.

Die bisherigen Ausführungen haben die Islamisierung gleichsam aus einer Weitwinkelperspektive betrachtet und sind zudem von der Vorstellung zweier getrennter Welten, hier Christentum, da Islam, ausgegangen. Glaubenswechsel sind aber unter weitaus komplizierten Bedingungen erfolgt, und so haben wir

52 Majer 1984. 
den Blick den im albanischen Raum so wichtigen Übergangsformen zuzuwenden, die freilich ebenfalls von Teilen der Forschung in stark ideologisierter Form behandelt werden. Gemeint sind hier die Bedeutung von Derwischorden, synkretistische Erscheinungen, der Glaubenswechsel von Familienvorständen (aber nicht der Familien, in denen besonders die Frauen lange den alten Glauben behielten), Glaubenswechsel nicht als abrupter Bruch, sondern als Übergang, wiederum im Zusammenhang der Familienstruktur, und schließlich das Kryptochristentum. „Albanien, Land der Derwische“, benannte die französische Orientalistin Nathalie Clayer eines ihrer Frühwerke. ${ }^{53}$ Tatsächlich sind unter albanischen Muslimen Derwischtarikate der unterschiedlichsten Ausrichtung stark vertreten, wobei wiederum deutliche regionale Unterschiede festzuhalten sind ${ }^{54}$ : Das südliche Albanien wurde am stärksten von Derwischorden durchdrungen, wobei der Bektashiorden besonders hervorragt. Wichtig ist, das Derwischtum bei den Albanern aber nicht auf diesen religiös und politisch auffälligen Orden zu beschränken, dessen Mitglieder in der Nationalbewegung eine führende Stellung einnahmen und sogar versuchten, den Bektashismus als albanische Nationalreligion darzustellen, da er im Gegensatz zu den drei anderen Religionen/ Konfessionen keinen Mittelpunkt außerhalb des albanischen Siedlungsgebietes besitze. Durch ihre Nähe zu christlichen volksreligiösen Bräuchen erreichten Bektashi gerade im orthodoxen Raum zahlreiche Christen, die an ihren Zeremonien teilnahmen und so einen allmählichen Übergang zum Islam vollzogen. Derwische siedelten sich zudem an religiös bedeutsamen Orten an, etwa in Kruja, bis 1478 Symbol des christlichen Widerstands, danach aber ein Ort der Verehrung Sari Saltıks. ${ }^{55}$ Weniger Sunniten, sondern Derwische trugen von muslimischer Seite zur Verbreitung synkretistischer Phänomene (gemeinsame Pilgerfahrten usw.) im albanischen Raum bei, auch wenn hier keine Mischreligion entstand, da die Teilnehmer unterschiedlichen sozioreligiösen Gemeinschaften angehörten, in welche die osmanische Gesellschaft gegliedert war. Da Derwische wiederholt Verfolgungen durch Sunniten ausgesetzt waren - so durch die Kadizadeli im 17. Jahrhundert oder durch die nach der Auflösung der mit dem Derwischmilieu verbundenen Janitscharen (1826) - entstand eine gewisse Distanz zum Sultan und Kalifen, was die herausgehobene Stellung der Bektashi in der Nationalbewegung ebenso erklärt wie die im Vergleich zu ihrer zahlenmäßigen Bedeutung geringen Beteiligung der Sunniten und vor allem geschlossener sunnitischer Gebiete an der sog. „Nationalen Wirtschaft“.

53 Clayer 1990; s. auch Clayer 1994.

54 Eine reiche Bibliographie bei Popovic 2010, 121-125; Popovic / Veinstein 1996; Rexhepagiqi 2003.

55 Kiel 1995. 
Wie angesprochen, entlastete der Glaubenswechsel christliche Steuerzahler. Da der Haushaltsvorstand die Familie gegenüber den osmanischen Behörden vertrat, wechselte gerade in schwer zugänglichen Gebieten oftmals nur dieser den Glauben, während der Rest der Familie christlich blieb; allmählich konvertierten dann die männlichen Mitglieder, so dass schließlich das Christentum auf die Frauen einer Familie beschränkt blieb, die als letzte den angestammten Glauben aufgaben. So bildete die Islamisierung gerade innerhalb von komplexen Familien einen Vorgang, der sich über einen längeren Zeitraum erstrecken konnte.

In vielen Provinzen des osmanischen Reiches verbreitet war das Kryptochristentum, und zwar vom Schwarzen Meer bis Albanien. Dabei handelt es sich um Christen, die sich nach außen als Muslime gaben, um Nachteile und Diskriminierungen zu vermeiden, im familiären Bereich aber ein christliches Leben führten. ${ }^{56}$ Dieses Phänomen ist einer der deutlichsten Belege für die strukturelle Diskriminierung der Nichtmuslime im osmanischen Reich. Zum Teil handelte es sich auch - so in Albanien - um Muslime, die zum Christentum übergetreten waren, dies aber nicht kundtun durften, da ihnen ansonsten der Tod drohte. Besonders die katholische Kirche versuchte, diese Menschen zu einem öffentlichen Glaubensbekenntnis zu zwingen, da dies aber, wie erwähnt, Lebensgefahr bedeutete, beschränkte sich um 1700 die Kirche auf eine Aufforderung zum Bekenntnis in einem rein innerkirchlichen Rahmen. Gefördert wurde das Kryptochristentum durch den - bereits angesprochenen - verbreiteten Brauch, dass nur das Familienoberhaupt, das allein mit den osmanischen Behörden in Berührung kam, den Glauben wechselte, Frauen und Kinder aber christlich blieben und christliche Bräuche beibehielten. Am Beispiel der albanischen Landschaft Has lässt sich zeigen, wie die Konvertiten langsam islamische Bräuche annahmen: nach der weitgehenden Islamisierung um 1633 berichtete ein katholischer Visitator:

Sie wollen sich nicht Untertanen der Türken nennen, weder durch ein Abhängigkeitsverhältnis noch durch Steuerzahlung; daher waren sie wie viele andere schlecht behandelt worden und sind zum Islam übergetreten, haben aber nur den Namen gewechselt, ohne in ihrem Herzen dem (alten) Glauben abzuschwören, jetzt aber haben sie begonnen, zu den Hoca zu gehen... mit dem Beschneider, der die Beschneidung vornimmt. ${ }^{57}$

Um 1853 lebten im katholischen Erzbistum Skopje 500 kryptochristliche Familien. Verbreitet war das Phänomen allgemein in eher abgelegenen Hügel- und Berggebieten, die nur wenig mit osmanischen Behörden in Berührung kamen (Shpat, Has, Rugova, Skopska crna gora).

56 Reinkowski 2003; Nikolaidu 1974; Skendi 1967; Maiocchi 2009.

57 Bartl 2006, 30. 
Der Zusammenbruch des kommunistischen Regimes in Albanien und die Umwälzungen in Kosovo und in geringerem Maße auch in Makedonien, die Entstehung einer starken Gastarbeiterdiaspora in Mittel- und Nordeuropa sowie die Kommunikationsrevolution des Internets haben die besprochenen Hauptdeutungen der Islamisierung aufgebrochen und relativiert. In Albanien sind seit zwei Jahrzehnten Religionen wieder zugelassen. Islamische Staaten von SaudiArabien, Iran bis zu Malaysia und in jüngster Zeit auch der Türkei betrieben eine von massiven Geldflüssen begleitete Religionspolitik unter den albanischen Muslimen. ${ }^{58}$ Gleichzeitig findet bei den albanischen Muslimen - wie bei den albanischen Christen - ein Prozess der Rückbesinnung auf Religion statt, bei der sich verschiedene Ebenen überlagern ${ }^{59}$ : genuine Religiosität, kulturelle Selbstvergewisserung, Neugier auf das lange Tabuisierte, wirtschaftliche Vorteile (z.B. aus Förderung des Tragens von Bärten und Kopftüchern, Renten und Spenden muslimischer Organisationen). Islamische Staaten verteilen Stipendien und fördern offen oder verdeckt Bildungseinrichtungen. Die Zahl junger Albaner, die ein Studium in islamischen Staaten absolviert haben und entsprechendes nahöstliches Gedankengut in ihre Heimat mitbringen, nimmt zu. Unmittelbar nach der Wende hat der damalige Ministerpräsident Sali Berisha Albanien in die „Organisation der Islamischen Konferenz“ bei den Vereinten Nationen geführt, wenn auch nur mit Beobachterstatus. Nicht nur innenpolitisch, sondern auch außenpolitisch hat sich die Lage der mehrheitlich muslimischen Albaner nach 1990 nachhaltig verändert: keine andere muslimische Gemeinschaft hegt stärkere amerikafreundliche Gefühle als die albanischen Muslime, die in den USA den Beschützer vor dem serbischen (und abgeschwächt auch vor dem makedonischen) Nationalismus sehen. Zudem streben die albanischen Staaten Albanien und Kosovo den Beitritt zur Europäischen Union an. Die albanischen Gesellschaften stehen so heute in einem sehr komplizierten Spannungsfeld: Die offizielle Außenpolitik betreibt die Eingliederung in euro-atlantische Strukturen (NATO-Mitgliedschaft Albaniens 2009), doch entziehen sich die armen Staaten nicht dem wirtschaftlichen Einfluss finanzkräftiger islamischer Staaten und auch der Türkei, die unter ihrer islamistischen Regierung seit einigen Jahren eine „,neu-osmanische“ Außenpolitik betreibt. Den albanischen Eliten ist bewusst, dass unter den gegenwärtigen weltpolitischen Bedingungen eine Forcierung des islamischen Charakters der albanischen Gesellschaften politische Nachteile zeitigen könnte. Die Regierungen in Tirana und Prishtina pflegen daher die traditionellen Vorstellungen der religiösen Indifferenz und der interreligiösen Toleranz. In Albanien wurde bis vor kurzem in Volkszählungen die Religionszugehörigkeit

58 Bougarel / Clayer 2001.

59 Endresen 2010, Endresen 2012. 
nicht erhoben, was Anlass zu Spekulationen über die echten oder vermeintlichen Missionserfolge der Religionen nach 1990 gab. Die Lage in den beiden Staaten ist religionspolitisch durchaus verschieden: Kosovo ist fast ganz muslimisch, in Albanien bestehen starke christliche Gemeinschaften. Obwohl muslimische Politiker beide Länder regieren, werden christliche Symbole gezielt politisch verwendet: Anzuführen ist hier der Staatskult um Mutter Theresa, die freilich vor allem als nationale Figur mit Weltgeltung und nicht als katholische Nonne dargestellt wird; auffallend ist dann der Bau einer katholischen Kathedrale mitten im fast rein muslimischen Prishtina. Beide Phänomene verweisen auf das starke politische Bedürfnis, sich vom Osten abzugrenzen, der sowohl als christlich-orthodox wie auch muslimisch wahrgenommen wird. Der kosovoalbanische Staatsgründerpräsident Ibrahim Rugova hat die Schaffung einer am Katholizismus ausgerichteten Nationalidentität wiederholt erwogen. ${ }^{60}$ Er vertrat dabei eine laizistisch geprägte Elite, die im jugoslawischen Sozialismus entstanden war und Identität als Alterität zur serbischen Nation verstand; die Rückkehr zu vermeintlichen katholischen Wurzeln sollte die Kosovo-Albaner im Gegensatz zu den als „östlich“ (da orthodox) empfundenen Serben als „westliche“ Nation darstellen. Solange die Kosovo-Albaner unter serbischer Herrschaft standen und dringend westlicher Hilfe bedurften, erhoben sich gegen diese Geschichtsdeutung kaum kritische Stimmen. Im traditionell aufgrund seiner geographischen Lage stärker mit dem katholischen Mittelmeerraum verbundenen Albanien wurde von den politischen Eliten eine vage katholisch grundierte mediterrane Identität vertreten, die sich weniger nach innen als an europäische Verhandlungspartner richtete. Dass dieser Grundkonsens brüchig ist, erwies sich im Jahre 2006, als der wichtigste Vertreter der katholisch grundierten Identitätsoption, Ismail Kadare, in eine Auseinandersetzung mit den kosovo-albanischen Literaturhistoriker Rexhep Qosja geriet. Kadare hatte in seinem Werk den Osten durchgehend als Bedrohung für die albanische Nation dargestellt. ${ }^{61}$ Mit Qosja teilt er einen ausgeprägten Nationalismus, ihre Geister scheiden sich aber an der Frage, was diese Nation denn ausmache. Kadare vertritt die Auffassung, dass die Zugehörigkeit zur abendländischen Welt, verkörpert durch die katholische Kirche, die eigentliche Grundlage albanischer Geschichte und Identität bilde und die Islamisierung eine Abweichung von dem vorgegebenen europäischabendländischen Weg der Albaner darstelle. In konsequenter Fortführung seines bereits zu kommunistischer Zeit negativen Bildes des Osmanischen Reiches stellt er dieses als das eigentlich Andere und Fremde in der albanischen Geschichte dar. Durch die Lösung vom orientalisch-muslimischen Erbe kehre Al-

60 Schmitt 2008b, 361.

61 Dazu Fn. 2 und auch Feraj 2006; Baleta 2002; Plasari 1992. 
banien nach Europa zurück - dass Kadare freilich nach innen durchaus nationalistisch-repressives Gedankengut vertritt, das kaum mit den in der EU verbreiteten Vorstellungen von Demokratie und Pluralismus in Einklang steht, sei hier nur am Rande angemerkt; die Gleichung ,,prowestlich ist auch demokratisch" gilt nicht in absoluter Form. Rexhep Qosja stellte sich dem vehement entgegen und vertrat ein bewusst positives Bild der osmanischen Herrschaft und der Bedeutung des Islam für die albanische Gesellschaft. Beide Kontrahenten gehören derselben Generation an, verraten aber die Prägungen durch die beiden unterschiedlichen Formen des albanischen Sozialismus - Qosja, der seine engere Heimat kaum verlassen hatte und nur in einer beschränkten Kommunikationswelt wahrgenommen wird, steht in der Tradition der Kaleshi-These, die Islamisierung habe die Albaner vor der Serbisierung bewahrt; Kadare hingegen, der teilweise in Paris lebt, wandelte sich vom verehrten Hofschriftsteller des Diktators und vermeintlichen Dissidenten zu einer Gestalt, die in Albanien als nationale Instanz verehrt wird und nach außen hin Deutungshoheit über die albanische Kultur beansprucht. Die von Kadare und Qosja ausgelöste Diskussion hält bis heute an; in Methode und Inhalt ist sie stark von äußeren Einflüssen gekennzeichnet. So haben junge islamisch ausgerichtete Intellektuelle die Saidsche Orientalismustheorie auf Albanien angewendet, freilich mit deutlicher ideologischer Ausrichtung: Wer die „Flucht aus dem Orient“ (Enis Sulstarova) beschreibt, verortet sein Land implizit im Orient und blickt bisweilen selbst nach Osten. Die intellektuelle Öffnung der albanischen Gesellschaften bedeutet also nicht automatisch eine Verwestlichung, vielmehr fügen sich albanische Intellektuelle in weitere diskursive Zusammenhänge ein und verwenden neue Theorien in ihrem weltanschaulichen Sinne. Die Debatte spiegelt komplizierte Bruchlinien in den albanischen Gesellschaften wider: 1) weil der Elitendiskurs durch das Internet rasche Verbreitung fand, dort aber bald ein Eigenleben entwickelte, das belegt, dass Diaspora und moderne technische Mittel das Deutungsmonopol der alten Eliten zwar aufbrechen, jedoch zumeist ergänzen und nicht verdrängen; 2) sich Angehörige der jungen Generation zu Worte melden, aber nicht einheitlich handeln; 3) weniger regionale als weltanschauliche Überzeugungen ausschlaggebend sind (Laizisten gegen Religiöse), 4) es sich überhaupt um die erste gesamtalbanische Identitätsdebatte handelt. Sie wirkt allmählich auch in die Politik über: Zuerst in Albanien, dann im Kosovo kamen Diskussionen um Verschleierung auf; die Regierung des Kosovo hatte einen streng laizistischen Kurs vertreten, während in Albanien eine klare Linie weniger erkennbar ist. Im Kosovo und in Makedonien werden immer wieder Fälle wahabitischen Einflusses diskutiert - wobei die politischen Eliten befürchten, dass die serbische Propaganda, wonach Kosovo ein Islamistenherd würde, Nahrung erhält. Regierungshandeln erfolgt hier stark mit dem Blick auf die Meinung der europäischen 
Außenwelt, ist aber auch von der EU abhängig, die sich in Gestalt der EULEX im Kosovo an inneren Angelegenheiten beteiligt. Auf der anderen Seite haben es die politischen Eliten mit zunehmend lautstarken Vertretern islamischer Organisationen zu tun, deren Wirken noch schlecht erforscht ist. Die Frage nach der Bewertung von Islamisierung und Islam stellt heute ein Kernproblem der albanischen Identitätsdiskussion dar. Die Stärke der Religionen ist schwer abzuschätzen; zu berücksichtigen ist dabei, dass über die eigentliche Religiosität und die Stellung des Islam im Alltag, jenseits der Verlautbarungen offizieller Vertreter, wenig bekannt ist. Zu unterstreichen ist, dass Sunniten und Vertreter des Bektashiorden keineswegs als Einheit gesehen werden dürfen, wie Spannungen unter anderem um die Tekke von Tetovo zeigen. ${ }^{62}$ Während die Sunniten die Bektashi als Teil der muslimischen Gemeinschaft sehen, pochen Bektashivertreter auf die herausragende Rolle ihres Ordens in der Nationalbewegung - nicht selten wird der Orden mit seinen synkretistischen Elementen sogar als Nationalreligion angesehen, in der die konkurrierenden Religionen des Christentums und des Islams ineinander fließen, und zwar zu einer national-albanischen Synthese.

Die albanischen Gesellschaften sind derzeit im Umbruch begriffen, und die Bedeutung der Religion wird neu ausverhandelt. Dies spiegelt sich in der Forschung wider. Während die albanische Historiographie sich bislang zu keiner selbstkritischen Betrachtung der eigenen Vergangenheit unter dem Kommunismus durchringen konnte, bildet doch ein Werk die Ausnahme. Nach etlichen internen Widerständen veröffentlichte 2007 Driton Egro, der jüngste Mitarbeiter des Tiranaer Akademieinstituts für Geschichte, eine Untersuchung zur albanischen Osmanistik. Das Buch ist in mehrerer Hinsicht symptomatisch: angesichts der heftigen Diskussionen um die Zeitgeschichte und das Zeitalter Skanderbegs war die osmanische Epoche während der Vorbereitung des Buches weniger im Brennpunkt des öffentlichen Interesses - dies hat sich, wie gezeigt, geändert; das Buch wurde in Albanien totgeschwiegen; der Autor hat sich in der Folge wieder in die Schar konformistischer Wissenschaftler eingefuigt und ist in jüngster Vergangenheit mit betont nationalen Stellungnahmen aufgefallen; schon im Buch hat der Autor wichtige Bereiche der Geschichte der Osmanistik vermieden. Ihm war es vor allem darum gegangen, die negative Bewertung des Osmanischen Reiches in einen geschichtlichen Zusammenhang, jenen der Diktatur Enver Hoxhas, zu stellen und tabuisierte Namen der Osmanistik zu rehabilitieren. Auch kritisierte er vehement die Selbstisolierung der albanischen

62 Die Arabati Baba Teqe ist im Dezember 2010 teilweise niedergebrannt http://shqip. time.mk/read/f2657c7d9c/925bb52cdb/index.html (gelesen am 8.3.2011). Der Verfasser hat die Teqe zuletzt im Juni 2010 besucht und ein Gespräch mit Baba Edmond Brahimaj geführt. 
Forschung und deren geringes Niveau und internationales Ansehen; zugleich forderte er das Ende einer rein empirischen Forschung und forderte eine stärkere Einbeziehung von Theorien. ${ }^{63}$ Er vermied es aber aufzuzeigen, dass die albanische Osmanistik sehr wohl eine wichtige nationalpolitische Aufgabe erfüllte, nämlich in der wissenschaftlich-politischen Kontroverse um die Bevölkerungsgeschichte der Albaner im früheren Jugoslawien. Insbesondere der zu höchsten Würden aufgestiegene Selami Pulaha stand hier in erster Linie, um vor allem mit der Edition des Defter von 1485 albanische Positionen zu verteidigen und den Anspruch auf Autochthonität mit Nachdruck zu vertreten. Egros methodische Bemerkungen treffen jedoch durchaus zu: Die albanische Forschung hat den Prozess der Islamisierung und die osmanische Herrschaft im allgemeinen stets in einem rein nationalen Rahmen betrachtet, den Vergleich mit dem osmanischen Balkan vermieden - hierin anderen Balkanhistoriographien nicht unähnlich und die internationale Forschung weitestgehend ausgeblendet. Viele Arbeiten weisen zudem einen rein technischen Charakter auf, das heißt, sie stellen Quellenmaterial vor, ohne es aber zu deuten (dies gilt für die Wirtschaftsgeschichte der osmanischen Zeit in deutlich geringerem Maße). Die oben geschilderte Debatte erfolgte auch weitgehend ohne Zutun der Historiker - nur ein alter Parteihistoriker meldete sich in einer etwas kruden Streitschrift zu Worte ${ }^{64}$. Den albanischen Historikern fehlt religionsgeschichtliches Rüstzeug, sie haben aber auch kein Interesse, es sich anzueignen. Sie überlassen daher dieses wichtige Feld Intellektuellen, Publizisten und religiösen Aktivisten. Nach 1990 ist die Zahl der Orientalisten noch weiter gesunken; zum einen starb die in der Zwischenkriegszeit ausgebildete Generation aus, zum anderen rückte kaum Nachwuchs mehr nach. Nicht die Orientalistik ist derzeit stark, sondern der orientalische Einfluss in Religion, Kultur und Politik. So findet die Debatte um die Bewertung der Islamisierung zunehmend in Internetforen statt, die aus dem Versagen wissenschaftlicher Publikationsorgane und dem Fehlen von Qualitätsmedien Nutzen ziehen. Die albanischen Gesellschaften sind sehr jung. Das sozialistische Erbe von Laizismus und religiöser Indifferenz, das ohnehin im wesentlichen Eliten und die städtische Bevölkerung betraf, gerät zunehmend unter Druck. Islam und albanischer Nationalismus müssen keinen Gegensatz mehr darstellen - dies gilt vor allem für die Albaner im früheren Jugoslawien. In Makedonien ist bei den Albanern der Laizismus stets äußerst schwach ausgebildet gewesen; im Kosovo ist die Wirtschaftskraft sehr bescheiden, der Staat instabil - wohin sich die junge Generation ausrichten wird, kann kaum abgeschätzt werden; in Albanien mit seiner starken christlichen Bevölkerung hingegen ist weniger zu erwarten, dass

63 Egro 2007. So in einem Gespräch mit der Zeitung Shekulli am 9. März 2009, http:// www.shekulli.com.al/2009/03/po-mbyllet-historia-empirike.html.

64 Frashēri 2006. 
die Islamisierung über alle gesellschaftlichen Schichten hinweg positiv betrachtet werden wird. Sowohl Kosovo wie auch Albanien sind derzeit durch politische Parteistreitigkeiten gelähmt, der Staat bietet kaum Identifikationsmöglichkeiten. Eine rasche Einbindung in die EU ist unrealistisch. So bieten sich neben der Nation auch Religionen als identitätsstiftende Orientierungsmuster an.

Um auf den Titel des Vortrags zurückzukommen: Eine Forschungsfrage ist die Islamisierung derzeit im albanischsprachigen Raum nicht, weil es kaum kompetente Forscher gibt; die Deutungshoheit hat nicht die Wissenschaft, vielmehr melden sich die unterschiedlichsten gesellschaftlichen Kräfte zu Wort: Bei der Bewertung der Islamisierung geht es im albanischen Zusammenhang um nichts weniger als um die Zukunft der albanischen Gesellschaften in Europa. Diese bilden keinen abgeschlossenen Kommunikationsraum mehr - politische und mediale Debatten erreichen den albanischen Balkan sehr schnell. Die Debatte um die Islamisierung erfolgt daher im Spannungsfeld inneralbanischer Deutungstraditionen und der Bewertung des Islam in den Ländern der EU. (Manuskript abgeschlossen im März 2013).

\section{Literaturverzeichnis}

Ahmeti, I., 1994: Kleri katolik shqiptar dhe letërsia. Ferizaj.

Anastasopoulos, A. (Hrsg.), 2008: The Eastern Mediterranean under Ottoman Rule, Crete, 1645-1840. Rethymno.

Baleta, A.,2002: Shqiptaret përballë terrorizmit intelektual të Falaçit. Tiranë.

Bartl, P., 1968: Die albanischen Muslime zur Zeit der nationalen Unabhängigkeitsbewegung (1878-1912). München.

Bartl, P., 2006: „Geistliche Visitationsberichte als Quellen zur albanischen Volks- und Kirchengeschichte: die Erzdiözese Skopje“, in: Kahl, Th. / Maksuti, I. / Ramaj, A. (Hrsg.): Die Albaner in der Republik Makedonien. Wien, Berlin, 21-37.

Bartl, P., 2007: Albania Sacra, Bd. 1. Wiesbaden.

Bartl, P., 2010: „Die katholische Kirche im Mittelalter und unter osmanischer Herrschaft", in: Schmitt, O.J. (Hrsg.): Religion und Kultur im albanischsprachigen Südosteuropa. Frankfurt a.M., Berlin, Bern u.a., 53-68.

Basha, A. M., 2010: „Muslim Communities under the Anti-Religious Regime in Albania (1945-1990)“, in: Schmitt, O.J. (Hrsg.): Religion und Kultur im albanischsprachigen Südosteuropa. Frankfurt a.M., Berlin, Bern u.a.,163-172.

Blumi, I., 2003: Rethinking the Late Ottoman Empire. A Comparative Social and Political History of Albania and Yemen 1878-1918. Istanbul.

Boeckh, K., 2005: „Zur Religionsverfolgung in Jugoslawien 1944-1953: Stalinistische Anleihen unter Tito“, in: Clewing, K. / Schmitt, O. J. (Hrsg.): Südosteuropa. Von vormoderner Vielfalt und nationalstaatlicher Vereinheitlichung. München, 431-461. 
Bougarel, X. / Clayer, N. (Hrsg.), 2001: Le nouvel Islam balkanique. Paris.

Ceka, E., 2006:,Die Debatte zwischen Ismail Kadare und Rexhep Qosja um die nationale Identität der Albaner", in: Südosteuropa 54/2 (2006), 451-460.

Ceka, E., 2010: „Atheismus und Religionspolitik im kommunistischen Albanien“, in: Schmitt, O. J. (Hrsg.):Religion und Kultur im albanischsprachigen Südosteuropa. Frankfurt a.M., Berlin, Bern u.a., 215-231.

Clayer, N.,1990: L'Albanie, pays des derviches. Berlin.

Clayer, N.,1994: Mystiques, État et Société. Les Halvetis dans l'aire balkanique de la fin du XVe siècle à nos jours. Leiden.

Clayer, N., 2002a: Religion et nation chez les Albanais, XIXe - XXe siècles. Istanbul o.J. (2002).

Clayer, N., 2002b: „The issue of ,the conversion to Islam“ in the restructuringof Albanian politics and identitiy", in: dies.: Religion et nation chez les Albanais, XIXe-XXe siècles. Istanbul o.J. (2002), 359-380.

Clayer, N., 2006: „Kufiri politik, kufiri etnik dhe shteti-komb. Shembulli i krahinës pranë kufirit shqiptaro-grek gjatë periudhës midis dy luftrave.“, in: Përpjekja 23 (2006), 147-165.

Clayer, N., 2007: Aux origines du nationalisme albanais. La naissance d'une nation majoritairement musulmane en Europe. Paris.

Clayer, N., 2008: „Behind the Veil. The Reform of Islam in Inter-War Albania or the Search for a ,Modern“ and ,European“ Islam“, in: Clayer, N. / Germain, E. (Hrsg.): Islam in Inter-War Europe. London, 128-155.

Clayer, N., 2009: „Religion, Nationsbildung und Gesellschaft“, in: Schmitt, O. J. / Frantz, E. A. (Hrsg.): Albanische Geschichte - Stand und Perspektiven der Forschung. München, 107- 117.

Clayer, N., 2010: „Construction de mosquées en Albanie, 1920-1939“, in: Archives de sciences sociales des religions 151 (2010), 91-105.

Clewing, K., 2006: „Religion und Nation bei den Albanern. Von Anspruch und Wirkungsmacht eines Religionen übergreifenden Nationenkonzepts“, in: Mosser, A. (Hrsg.): Politische Kultur in Südosteuropa. Frankfurt a.M. u.a., 147-181.

Demiraj, B. (Hrsg.), 2004: Kuvendi i Arbënit 1703 në 300-vjetorin e mbajtjes së tij. Prishtina.

Demiraj, B., 2010: „Shqiptar - The Generalization of This Ethnic Name in the XVIIIth Century", in: ders. (Hrsg.): Wir sind die Deinen. Studien zur albanischen Sprache, Literatur und Kulturgeschichte, dem Gedenken an Martin Camaj (1925-1992) gewidmet. Wiesbaden, 533-565.

De Rapper, G., 2008: „Musulmans convertis et chrétiens autochthones en Albanie du Sud", in: de Rapper, G. / Sintès, P. (Hrsg.): Nommer et classer dans les Balkans. Athen, 351-367.

Deusch, Engelbert, 2009: Das k.(u.)k. Kultusprotektorat im albanischen Siedlungsgebiet. Weimar, Wien, Köln.

Duka, F., 2009: Shekujt osmanë në hapësirën shqiptare (studime dhe dokumente). Tirana.

Egro, D., 2007: Historia dhe ideologjia. Tirana. 
Egro, D., 2010: „Islam in the Albanian Lands (XVth - XVIIth Century)“, in: Schmitt, O. J. (Hrsg.): Religion und Kultur im albanischsprachigen Südosteuropa. Frankfurt a.M., Berlin, Bern u.a., 13-51.

Endresen, C., 2010: „,Do not look to church and mosque“? Albania's post-Communist clergy on nation and religion", in: Schmitt, O. J. (Hrsg.): Religion und Kultur im albanischsprachigen Südosteuropa. Frankfurt a.M., Berlin, Bern u.a.,233-258.

Endresen, C., 2012: Is the Albanian's religion really „Albanianism“? Wiesbaden.

Feraj, H., 2006: Skicë e mendimit politik shqiptar, 3. Auflage. Tirana.

Frantz, E., 2009a: „Gewalt als Faktor der Desintegration im Osmanischen Reich - Formen von Alltagsgewalt im südwestlichen Kosovo in den Jahren 1870-1880 im Spiegel österreichisch-ungarischer Konsulatsberichte“, in: Südost-Forschungen 68 (2009), 184-204.

Frantz, E., 2009b: „Violence and its Impact on Loyalty and Identity Formation in Late Ottoman Kosovo: Muslims and Christians in a Period of Reform and Transformation“, in: Journal of Muslim Minority Affairs 29 (2009), Heft 4, 455-468.

Frantz, E. A., 2010: „Religiös geprägte Lebenswelten im spätosmanischen Kosovo“, in: Schmitt, O. J. (Hrsg.): Religion und Kultur im albanischsprachigen Südosteuropa. Frankfurt a.M., Berlin, Bern u.a., 127-149.

Frantz, E., 2011: „Catholic Albanian Warriors for the Sultan in Late Ottoman Kosovo: The Fandi as a Socioprofessional Group and their Identity Patterns“, in: Clayer, N. / Grandits, H. / Pichler, R. (Hgg.): Conflicting Loyalties in the Balkans: The Great Powers, the Ottoman Empire and Nation-Building. London, S. 182-201.

Frashēri, Kristo, 2006: Identiteti kombëtas shqiptas dhe qështje të tjera. Tiranë.

Giakoumis, K., 2010: „,The Orthodox Church in Albania under Ottoman Rule (15th19th Century)", in: Schmitt, O.J. (Hrsg.): Religion und Kultur im albanischsprachigen Südosteuropa. Frankfurt a.M., Berlin, Bern u.a., $69-110$.

Glabinas, A., 1985: He Orthodoxe Ekklesia tes Albanias. Thessalonike.

Ǵorgiev, D., 2006/07: „Siedlungsverhältnisse im makedonisch-albanischen Grenzgebiet im 15. und 16. Jahrhundert (nach osmanischen Quellen)“; in: Südost-Forschungen 65/66 (2006/07), 117-136.

Historia e popullit shqiptar. Bd.1., Tirana 2002.

Idrizi, I., 2010: Das Konzept des Neuen Menschen im kommunistischen Albanien 1961-1971. Diplomarbeit, Wien. (einsehbar unter http://othes.univie.ac.at/9344/1/2010-0413_0409931.pdf).

Kadare, I., 2006: Identiteti evropian i Shqiptarëve. Sprovë. Tiranë.

Kaleshi, H., 1975: „Das türkische Vordringen auf dem Balkan und die Islamisierung Faktoren für die Erhaltung der ethnischen und nationalen Existenz des albanischen Volkes“, in: Südosteuropa unter dem Halbmond. München, 125-138.

Kiel, M.,1995: „A Note on the Date of the Establishment of the Bektashi Order in Albania“, in: Popovic, A. / Veinstein, G. (Hrsg.): Bektachiyya. Études sur l'ordre mystique des Bektachis et les groupes relevant de Hadji bektach. Istanbul, 263-269. 
Köhbach, M., 1986: „Nordalbanien in der zweiten Hälfte des 18. Jahrhunderts. Das Paşalık Shkodër unter der Herrschaft der Familie Bushatlli“, in: Beitl, K. u.a. (Hrsg.): Albanien-Symposion 1984. Kittsee, 133-180.

Kondis, B., 1976: Greece and Albania. Saloniki.

Kurti, D. / Sirdani, M., 1999: Mbi kontributin e elementit katolik në Shqipëri.(Nachdruck). Tirana.

Maioicchi, L., 2009: „The Coexistence of Catholic and Muslim Communities in $18^{\text {th }}$ Century Kosovo“, in: Kahl, Th. / Lienau, C. (Hrsg.): Christen und Muslime. Interethnische Koexistenz in südosteuropäischen Peripheriegebieten. Wien, Berlin, 97-111.

Majer, H. G., 1984: „Albaner und Bosnier in der osmanischen Armee. Ein Faktor der Reichsintegration im 17. und 18. Jahrhundert“, in: Grothusen, K. D. (Hrsg.): Jugoslawien. Integrationsprobleme in Geschichte und Gegenwart. Göttingen, 105-117.

Marlekaj, L., 2008: Pjetër Bogdani e Shqipnia e kohës së tij. Shkodra.

Marquet, O., 1997: Pjetër Bogdani. Letra dhe dokumente nga Arkivi i Kongregatës „de Propaganda Fide" si dhe nga Arkivat Sekrete të Vatikanit. Shkodra.

Morozzo della Rocca, R., 1990: Nazione e religione in Albania 1920-1944. Bologna.

Naçi, Stavri, 1986: Pashallëku i Shkodrës (1796-1831). Tirana.

Nadin, L., 2008: Migrazioni e integrazione. Il caso degli albanesi a Venezia (1479-1552). Rom.

Nikolaidu, E., 1974: Hoi Kryptochristianoi tes Spathias (arches 18u ai.-1912). Ioannina.

Peters, M. W. E., 2007: Der älteste Verlag Albaniens und sein Beitrag zur Nationalbewegung, Bildung und Kultur. Die „Buchdruckerei der Unbefleckten Empfängnis“ zu Shkodra (18701945). Hamburg.

Peyfuss, M. D., 1974: Die aromunische Frage. Wien.

Plasari, A., 1992: Vija e Teodosit rishfaqet. Tirana. (italienisch: La linea di Teodosio. Alle origini della questione albanese. Nardò (Lecce) o.J.).

Popovic, A. / Veinstein, G. (Hrsg.), 1996: Les Voies d'Allah. Les ordres mystiques dans le monde musulman des origines à nos jours. Paris.

Popovic, A., 2010: „Les confréries mystiques musulmanes dans 1'espace albanophone (XIXe-Xxe s.)“, in: Schmitt, O. J. (Hrsg.): Religion und Kultur im albanischsprachigen Südosteuropa. Frankfurt a.M., Berlin, Bern u.a., 111-125.

Radoja, E. / Berisha, A. N. (Hrsg.), 2003: Kuvendi i Arbënit 1703. Prishtina.

Reinkowski, M., 2003: „Kryptochristen und Kryptojuden im Islam“, in: Saeculum 54/1 (2003), 13-37.

Reinkowski, M., 2005: Die Dinge der Ordnung. Eine vergleichende Untersuchung über die osmanische Reformpolitik im 19. Jahrhundert. München.

Rexhepagiqi, J., 2003: Dervishet dhe teqetë në Kosovë, në Sanxhak dhe në rajonet tjera përreth. Peja.

Schmidt-Neke, M., 2009: „Zwischen Kaltem Krieg und Teleologie: Das kommunistische Albanien als Objekt der Zeitgeschichtsforschung“, in: Schmitt, O. J. / Frantz, E. A. (Hrsg.): Albanische Geschichte - Stand und Perspektiven der Forschung. München, 131-147. 
Schmitt, O. J. / Frantz,E. A. (Hrsg.), 2009: Albanische Geschichte - Stand und Perspektiven der Forschung. München.

Schmitt, O. J., 2000: „Paul Angelus, Erzbischof von Durazzo, und seine Bedeutung für den Türkenkampf Skanderbegs“, in: Thesaurismata 30 (2000), 127-161.

Schmitt, O. J., 2001: Das venezianische Albanien (1392-1479). München.

Schmitt, O. J., 2005: „Genosse Aleks und seine Partei oder: Zu Politik und Geschichtswissenschaft im kommunistischen Albanien (1945-1991)“, in: Krzoska, M. / Maner, H. Ch. (Hrsg.): Beruf und Berufung. Geschichtswissenschaft und Nationsbildung in Ostmittel- und Südosteuropa im 19. und 20. Jahrhundert. Münster, 143-166.

Schmitt, O. J., 2008a:,,,Flucht aus dem Orient'? Kulturelle Orientierung und Identitäten im albanischsprachigen Balkan“, in: Görner, F. (Hrsg.): Stabilität in Südosteuropa eine Herausforderung für die Informationsvermittlung. Berlin, 12-27.

Schmitt, O. J., 2008b: Kosovo - kurze Geschichte einer zentralbalkanischen Landschaft. Wien.

Schmitt, O. J., 2009: Skanderbeg - der neue Alexander auf dem Balkan. Regensburg.

Schwandner-Sievers, S./ Fischer, B. J., 2002: Albanian Identities. London.

Shpuza, G.,1979: Kryengritja e fshatarësisë së Shipërisë Mesme e udhëhequer nga Haxhi Qamili. Tirana.

Skendi, S., 1967: „Crypto-Christianity in the Balkan Area in the Balkan Area under the Ottomans“, in: Slavic Review 26 (1967), 227-246.

Stadtmüller, G., 1955: „Die Islamisierung bei den Albanern“, in: Jahrbücher für Geschichte Osteuropas. Neue Folge 3 (1955), 404-429.

Sulstarova, E., 2006: Arratisje nga lindja. Orientalizmi shqiptar nga Naimi te Kadareja. Tiranë.

Tönnes, B., 1980: Sonderfall Albanien. Enver Hoxhas „eigener Weg“ und die historischen Ursprünge seiner Ideologie. München.

Winnifrith, Tom J., 2002: Badlands - Borderlands - A History of Northern Epirus / Southern Albania. London.

Xhufi, P., 2006: Dilemat e Arbërit. Tirana. 